\title{
NERACA SUMBER DAYA AIR DI DAERAH ALIRAN SUNGAI ALANG WONOGIRI
}

\author{
Bayu Yoga Pratama1), Rintis Hadiani ${ }^{2)}$, Solichin ${ }^{3)}$ \\ 1) Mahasiswa Fakultas Teknik, ProdiTeknik Sipil, Universitas Sebelas Maret \\ 2) Pengajar Fakultas Teknik, ProdiTeknik Sipil, Universitas Sebelas Maret \\ 3) Pengajar Fakultas Teknik, ProdiTeknik Sipil, Universitas Sebelas Maret \\ Jl. Ir. Sutami 36A, Surakarta 57126; Telp. 0271-634524. \\ Email:uchiabayu@gmail.com
}

\begin{abstract}
Bayu Yoga Pratama, 2018 Balance of water resources In the Watershed Alang Wonogiri river. Thesis. Civil Engineering Program, Sebelas Maret University

In each region will definitely be experiencing population growth. Similarly, in the area of Wonogiri whose the population the longer it continues to experience growth. There are many things that will happen if the population growth increases, i.e the use of land for residential, urban, and industrial will increase. This effect on amount of water usage on the rise, if water usage is increasing then it automatically increasing water demand as well. As the development of technology, it can belp us to find out about the comparison between water needs with the availability of water in nature, with a look at some of the factors that can affect the potential of the surface water that is among other things the conditions DAS, a variety of physical forms of water resources, a spooler area, volume, aspect and climate, the influence of water resources management aspect (Sunaryo. et. Al.,2015). By knowing all those things and assisted with the development of technology, then this research can be done.

Data collection is the first step of this research, then the data analysis and testing the validity of the data using the RAPS method. Calculations for area rain using Polygon Thiessen. Polygon Thiessen was obtained from the help of ArcGIS software. To find out potential evapotranspiration is done with the help of cropwatt software. The debit calculation has done by the NRECA method and then the water discharge value is obtained. Furthermore, for water needs, namely the need for RKI, Animal Husbandry, Fisheries, river water needs, and irrigation, the data can be seen in Wonogiri Dalam Angka.

The results of the comparison of water requirements and the availability of water in the Alang Wonigiri Central Java 2017 watershed have the largest deficit yield of 16460014,494 $\mathrm{m3} / \mathrm{month}$ and a map the results of the use of water index is red while the water balance predictions for results year 2018 obtained results with the greatest value of 23932009.41 deficits $\mathrm{m3} / \mathrm{month}$ and the map results index the use of water is red as well.
\end{abstract}

Keywords: Water Balance, NRECA, predictions of rain areas and needs water, Water Balance Maps, DAS Alang Wonogiri, Central Java.

\begin{abstract}
Abstrak
Bayu Yoga Pratama, 2018 Neraca Sumber Daya Air Di Daerah Aliran Sungai Alang Wonogiri. Skripsi. Program Teknik Sipil Fakultas Teknik Universitas Sebelas Maret, Surakarta.

Pada Setiap daerah pasti akan mengalami pertumbuhan penduduk. Begitu juga pada daerah Wonogiri yang penduduknya semakin lama terus mengalami pertumbuhan. Ada banyak hal yang akan terjadi jika pertumbuhan jumlah penduduk semakin meningkat, yaitu penggunahan lahan untuk pemukiman, perkotaan, dan industri akan meningkat. Hal ini berpengaruh pada jumlah penggunaan air meningkat, jika penggunaan air meningkat maka otomatis kebutuhan air akan meningkat pula. Seiring perkembangan teknologi maka dapat membantu kita untuk mengetahui tentang perbandingan antara kebutuhan air dengan ketersediaan air yang ada di alam, dengan melihat beberapa faktor yang dapat mempengaruhi potensi air permukaan yaitu antara lain kondisi DAS, aneka bentuk fisik sumber daya air, luas, volume tampungan, pengaruh iklim, dan aspek pengeoloaan sumber daya air (Sunaryo.et.al.,2015). Dengan mengetahui semua hal itu dan di bantu dengan perkembangan teknologi maka penelitian ini dapat di lakukan.

Pengumpulan data merupakan langkah awal penelitian ini dilakukan, kemudian analisis data dan melakukan uji validitas data menggunakan metode RAPS. Perhitungan untuk hujan wilayah menggunakan Polygon Thiessen. Polygon Thiessen di peroleh dati bantuan software ArcGIS. Untuk mengetahui evapotranspirasi potensial dilakukan dengan bantuan software cropwatt. Perhitungan debit dilakukan dengan metode NRECA dan selanjutnya diperoleh nilai debit air. Selanjutnya untuk kebutuhan air yaitu kebutuhan RKI, Peternakan, Perikanan, kebutuhan air sungai, dan irigasi di peroleh data yang dapat dilihat dalam Wonigiri Dalam Angka.

Hasil dari perbandingan kebutuhan air dan ketersediaan air di DAS Alang Wonigiri Jawa Tengah 2017 di dapatkan hasil defisit terbesar bernilai $16460014,494 \mathrm{~m}^{3} /$ bulan dan peta hasil dari indeks

Pemakaian air berwarna merah, sedangkan hasil prediksi neraca air untuk tahun 2018 didapat hasil defisit dengan nilai terbesar 23932009,41 m³/bulan dan peta hasil indeks pemakain air berwarna merah juga.
\end{abstract}


Kata kunci : NRECA, Neraca Air, Prediksi Hujan wilayah dan kebutuhan air, Peta Neraca Air, DAS Alang Wonogiri Jawa Tengah.

\section{PENDAHULUAN}

Air adalah salah satu unsur penting bagi kehidupan manusia. Di alam sendiri pun sudah tersedia banyak sumber air, akan tetapi terkadang manusia tidak bisa memanfaatkan sumber air tersebut. Bahkan sering terjadi kekeringan atau kekurangan akan ketersediaan air. Untuk itu kita perlu suatu teknik dan strategi untuk memanfaatkan sumber air agar kita bisa selalu menjaga ketersediaan air untuk kebutuhan manusia.

Secara umum potensi air permukaan di tentukan oleh beberapa faktor antara lain kondisi DAS, aneka bentuk fisik sumber daya air, luas, volume tampunganya entah itu alami maupun buatan, pengaruh iklim, dan aspek pengelolaan sumber daya air (Sunaryo.et.al.,2015). Dan untuk penyusuan strategi pengelolaan sumber daya air, di perlukan data mengenai neraca ketersediaan air dan kebutuhan air.

Untuk saat ini ketersediaan air di wongiri harus mencukupi kebutuhan air di seluruh wilayah soloraya dan sekitarnya. Di wonogiri juga terdapat banyak sekali sungai yang dapat menyuplai kebutuhan air tersebut. Salah satu contohnya adalah sungai Alang.Sungai alang sendiri meliputi 5 kecamatan di provinsi Jawa Tengah yaitu Kecamatan Pracimantoro, Kecamatan Song Putri, Kecamatan Nawangan, Kecamatan Giritontro, dan Kecamatan Trukan.

Dengan semakin bertambahnya jumlah penduduk di wilayah soloraya, maka bertambah pula kebutuhan akan penggunaan air, antara lain untuk memenuhi kebutuhan pokok sehari-hari, kebutuhan industi, energi listrik tenaga air, wisata, dan di sektor pertanian. Indikator untuk melihat seberapa besar kebutuhan air dibandingkan dengan jumlah air yang tersedia adalah neraca air. Neraca sumber daya air adalah informasi tentang imbangan potensi, ketersediaan, dan penggunaan atau kebutuhan sumber daya air pada kurun waktu tertentu (SNI 6728.1:2015). Agar tidak terjadi defisit (kekurangan) air di DAS Alang alangkah baik nya melakukan penelitian prediksi kebutuhan dan ketersedian air di tahun yang akan datang dengan melihat tahun-tahun yang sudah terjadi. Penelitian ini mencari neraca air tahun 2017 dan pada tahun 2018 akan di prediksi, diharapkan penelitian itu dapat berupa peta indeks neraca air dengan simbol-simbol warna yang dapat menggambarkan apa yang sedang di alami agar dapat di pahami oleh masyarakat dengan mudah. Pemetaan itu sendiri nantinya di buat dengan software yang dapat menunjang pembuatanya contohnya seperti software ArcGIS.

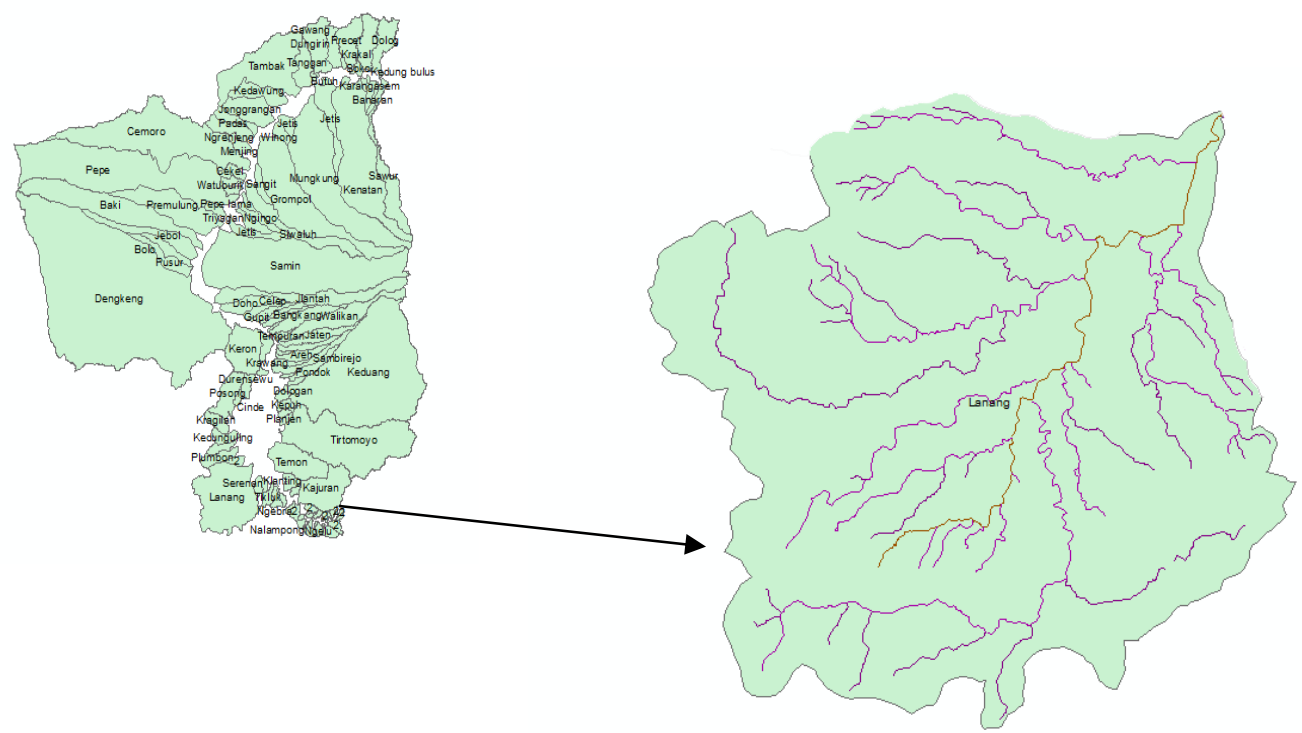

Gambar 1 Peta DAS Alang

\section{LANDASAN TEORI Dasar Teori}

Data merupakan bahan yang penting pada setiap penelitian akan tetapi belum bisa menjadi sebuah hasil, sehingga masih memerlukan pengolahan agar sebuah data tersebut dapat memberikan hasil yang diharapkan oleh seorang 
peneliti. Berdasarkan cara memperolehnya, data dapat dibedakan menjadi 2 jenis yaitu data primer dan data sekunder.

Data yang diperoleh dari alat pencatat bisa jadi tidak panggah karena: alat pernah rusak, alat pernah pindah tempat, lokasi alat terganggu, atau terdapat data tidak sah. Uji konsistensi dapat dilakukan dengan lengkung massa ganda (double mass curve) untuk stasiun hujan $\geq 3$ (tiga), dan untuk individual stasiun (stand alone station) dengan cara RAPS (Rescaled Adjusted Partial Sus), Sri Harto (2000).

Metode Inversed square Distance adalah metode yang akan digunakan untuk mengisi data hujan yang hilang pada penelitian ini. Metode ini selain menggunakan data hujan juga mempertimbangkan jarak antar stasiun hujan terdekat.

Pada penelitian ini untuk menghitung hujan wilayah adalah menggunakan metode polygon thiessen. Metode ini dilihat dari memperhitungkan bobot dari masing-masing stasiun hujan yang mewakili luasan di sekitarnya.

Berdasarkan SNI 6728.1:2015, Debit andaan yang digunakan adalah debit andalan Q80 maksudnya adalah debit dengan kemungkinan terlampaui 80\%. Pada metode debit andalan,ketersedian air diperhitungkan berdasarkan analisis data aliran dengan tingkat resiko kegagalan tertentu.

Kebutuhan air irigasi dihitung menggunakan data areal irigasi, jenis tanah, jadwal kalender tanam, evapotranpirasi tanaman acuan, efisiensi saluran irigasi dan data hujan efektif.

Kebutuhan Air Rumah Tangga, Perkotaan dan Industri (RKI). Berdasarkan SNI 6728.1-2015, Hasil perhitungan kebutuhan air dibandingkan dengan data pengambilan air baku oleh PDAM terkait.

Perhitungan kebutuhan air rata-rata untuk peternakan tergantung pada populasi/jumlah ternak dan jenis ternak ( SNI 6728.1-2015). Secara umum kebutuhan air untuk ternak dapat diestimasikan dengan cara mengalikan jumlah ternak dengan tingkat kebutuhan air.

Berdasarkan SNI 6728.1-2015, Perlindungan aliran pemeliharaan sungai dilakukan dengan mengendalikan ketersediaan debit andalan 95\%,yaitu aliran air (m3/detik) yang selalu tersedia dalam 95\% waktu pengamatan, atau hanya paling banyak 5\% kemungkinan aliran tersebut tidak tercapai.

Untuk menghitung debit menggunakan metode NRECA dan sebelum mencari NRECA terlebih dahulu mencari evapotranspirasi potensial menggunakan metode Penman-Monteith.

Prediksi data pada penelitian ini adalah prediksi curah hujan tahun 2018 dan kebutuhan air untuk irigasi dan non irigasi tahun 2017 dan 2018.

Pada penelitian ini software GIS digunakan untuk mencari poligon thiessen, peta batas DAS dan untuk membuat peta hasil indeks neraca air yang sudah di hitung.

\section{METODE PENELITIAN}

Penelitian ini menggunakan data sekunder. Data sekunder meliputi data hujan harian stasiun Hujan Pracimantoro, Giritontro, dan WD Nawangan, data klimatologi, peta DAS Alang, data kebutuhan air irigasi dan non irigasi.

\section{HASIL DAN PEMBAHASAN}

\section{Data Curah Hujan}

Data curah hujan yang digunakan pada penelitian ini merupakan data hujan dari stasiun. Data evapotrasnpirasi merupakan data yang di peroleh dari stasiun Klimatologi Wonogiri. Sebagai contoh, data hujan dan evapotranspirasi.

\section{Uji Kepanggahan}

Data hujan yang diperoleh belum dapat langsung digunakan dalam analisis data. Data Hujan perlu diuji konsistensinya dengan uji panggah.Uji panggah dalam penelitian ini menggunakan metode RAPS. Uji pangah menggunakan 3 stasiun hujan yaitu dari stasiun Pracimanroro stasiun Giritontro, dan stasiun Wd. Nawangan. Pada penelitian ini data hujan yang digunakan selama 10 tahun 2008-2017. Data yang dianalisis menggunakan 
metode ini dikatakan panggah atau konsinten apabila nilai $\mathrm{Q} / \mathrm{n}$ kritik dan $\mathrm{R} / \mathrm{n}$ lebih kecil dari nilai $\mathrm{Q} / \mathrm{n}$ kritik dan $\mathrm{R} / \mathrm{n}$, contoh perhitungan uji kepanggahan data bulanan pos hujan pracimantoro.

Tabel 1 Hasil perhitungan metode RAPS kecamatan Pracimantoro

\begin{tabular}{|c|c|c|c|c|c|c|}
\hline \multicolumn{7}{|c|}{ Pracimantoro } \\
\hline $\mathrm{NC}$ & Tahun & Hujan & SK* & $\mathrm{SD}^{\wedge} 2$ & SK** & $\left|\mathrm{SK}^{* *}\right|$ \\
\hline 1 & 2006 & 0 & $-2617,2$ & 342486,8 & $-1,46163$ & 1,461625669 \\
\hline 2 & 2007 & 0 & $-2617,2$ & 342486,8 & $-1,46163$ & 1,461625669 \\
\hline 3 & 2008 & 1424 & $-1193,2$ & 71186,31 & $-0,66637$ & 0,666365485 \\
\hline 4 & 2009 & 1200 & $-1417,2$ & 100422,8 & $-0,79146$ & 0,791462593 \\
\hline 5 & 2010 & 1317 & $-1300,2$ & 84526 & $-0,72612$ & 0,726121693 \\
\hline 6 & 2011 & 1619 & $-998,2$ & 49820,16 & $-0,55746$ & 0,557463986 \\
\hline 7 & 2012 & 1548 & $-1069,2$ & 57159,43 & $-0,59712$ & 0,597115301 \\
\hline 8 & 2013 & 2051 & $-566,2$ & 16029,12 & $-0,31621$ & 0,316205278 \\
\hline 9 & 2014 & 1261 & $-1356,2$ & 91963,92 & $-0,7574$ & 0,75739597 \\
\hline 10 & 2015 & 1242 & $-1375,2$ & 94558,75 & $-0,76801$ & 0,768006885 \\
\hline \multicolumn{2}{|c|}{ Jumlah } & 11662 & & & & \\
\hline \multicolumn{2}{|c|}{ Rata-rata } & 1166,2 & & & & \\
\hline \multicolumn{2}{|c|}{$\mathrm{SD}$} & 663,2237 & & & & \\
\hline \multicolumn{2}{|c|}{ SK** Max } & 1,461626 & & & & \\
\hline \multicolumn{2}{|c|}{$\mathrm{SK}^{* *} \mathrm{Min}$} & 0,316205 & & & & \\
\hline $\mathrm{Q}$ & 1,461626 & & 0,462207 & $<$ & 1,1 & PANGGAH \\
\hline $\mathrm{R}$ & 1,14542 & & 0,362214 & $<$ & 1,34 & PANGGAH \\
\hline
\end{tabular}

\section{Hujan Wilayah}

Hujan wilayah dihitung dengan menggunakan metode Poligon Thiessen. Metode ini dipilih karena jumlah data hujan yang dimiliki 3 stasiun, sehungga metode Poligon Thiessen dipandang sebagai metode yang paling efektif dan paling mudah untuk menghitung hujan wilayah Daerah Aliran Sungai (DAS) Alang.

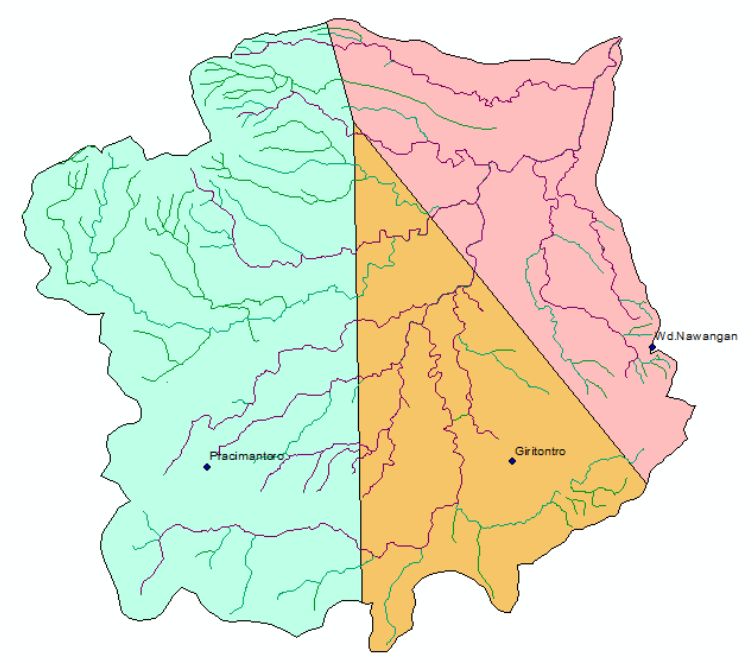

Gambar 2 Polygon Thiessen 
Tabel 2 Hasil evapotranspirasi Potensial

\begin{tabular}{lccccc} 
BULAN & $\begin{array}{c}\text { TEMPERATUR } \\
\text { MAKSIMUM } \\
\left({ }^{\mathrm{O}} \mathrm{C}\right)\end{array}$ & $\begin{array}{c}\text { TEMPERATUR } \\
\text { MINIMUM } \\
\left({ }^{\circ} \mathrm{C}\right)\end{array}$ & $\begin{array}{c}\text { KELEMBABAN } \\
(\%)\end{array}$ & $\begin{array}{c}\text { KECEPATAN } \\
\text { ANGIN } \\
(\mathrm{KM} / \mathrm{HR})\end{array}$ & $\begin{array}{c}\text { SINAR } \\
\text { MATAHARI } \\
(\%)\end{array}$ \\
\hline JANUARI & 29,1 & 26,5 & 97,5 & 381,6 & 6,8 \\
\hline FEBRUARI & 29,9 & 23,6 & 96,6 & 284.1 & 4.5 \\
\hline MARET & 29,0 & 23,8 & 90,6 & 420,3 & 4,2 \\
\hline APRIL & 29,5 & 23,7 & 96,2 & 628 & 4,8 \\
\hline MEI & 28,9 & 23,2 & 97,3 & 1212,3 & 5,7 \\
\hline JUNI & 29,0 & 22,4 & 97,2 & 990,2 & 7,6 \\
\hline JULI & 28,5 & 21,2 & 96,5 & 1598,4 & 8,2 \\
\hline AGUSTUS & 29,2 & 22,7 & 97,0 & 1420,8 & 8,4 \\
\hline SEPTEMBER & 29,8 & 23,8 & 97,2 & 2535,3 & 8,8 \\
\hline OKTOBER & 30,5 & 24,6 & 96,7 & 1499,2 & 8,3 \\
\hline NOVEMBER & 29,5 & 24,2 & 96,5 & 464,6 & 5,3 \\
\hline DESEMBER & 28,7 & 24,1 & 97,9 & 602,2 & 3,2 \\
\hline
\end{tabular}

\section{Prediksi Hujan Wilayah}

Pada penelitian ini prediksi hujan wilayah untuk memprediksi hujan wilayah DAS Alang pada tahun 2018. Metode yang digunakan dalam mencari prediksi hujan wilayah 2018 adalah Arima dengan bantuan software Minitab 18.

Tabel 3 Hasil Prediksi Hujan Wilayah Metode Arima Menggunakan Minitab

Bulan Prediksi Arima Prediksi yang Digunakan

\begin{tabular}{ccc} 
& curah hujan $(\mathrm{mm})$ & curah hujan $(\mathrm{mm})$ \\
\hline jan & 253,827 & 253,827 \\
\hline feb & 196,516 & 196,516 \\
\hline mar & 230,951 & 230,951 \\
\hline apr & 41,038 & 41,038 \\
\hline mei & $-9,381$ & $-9,381$ \\
\hline jun & $-47,363$ & $-47,363$ \\
\hline jul & $-49,861$ & $-49,861$ \\
\hline ags & $-51,444$ & $-51,444$ \\
\hline sep & 238,275 & 238,275 \\
\hline okt & 60,116 & 60,116 \\
\hline nov & 178,961 & 178,961 \\
\hline des & 193,330 & 193,330 \\
\hline
\end{tabular}

\section{Debit Andalan}


Pada penelitian ini debit andalan yang digunakan adalah Q80\%, maksudnya adalah debit dengan kemungkinan terlampaui $80 \%$. Pada metode debit andalan, ketersediaan air diperhitungkan berdasarkan analisis data aliran dengan tingkat resiko kegagalan tertenu.

Tabel 4 Hasil Perhitungan Debit Andalan Metode Weibull tahun 2017

\begin{tabular}{|c|c|c|c|c|c|c|c|c|c|c|c|c|c|c|}
\hline \multirow{2}{*}{$\begin{array}{c}\text { Data } \\
\text { Ke- }\end{array}$} & \multirow{2}{*}{$\begin{array}{c}\text { Prob. } \\
(\%)\end{array}$} & \multicolumn{12}{|c|}{ Debit NRECA $\left(\mathrm{m}^{3} / \mathrm{dtk}\right)$} & \multirow{2}{*}{ Total } \\
\hline & & Jan & Feb & Mar & Apr & Mei & Jun & Jul & Ags & Sep & Okt & Nop & Des & \\
\hline 1 & 9,1 & 14,88 & 18,19 & 22,42 & 13,11 & 11,98 & 9,64 & 7,02 & 5,96 & 7,06 & 28,30 & 13,16 & 15,57 & 167,27 \\
\hline 2 & 18,2 & 13,97 & 15,32 & 12,02 & 10,72 & 7,71 & 6,35 & 4,93 & 3,94 & 3,38 & 20,59 & 11,34 & 11,73 & 122,02 \\
\hline 3 & 27,3 & 12,27 & 9,48 & 11,98 & 10,60 & 7,33 & 6,09 & 4,69 & 3,75 & 3,10 & 2,72 & 3,87 & 8,41 & 84,28 \\
\hline 4 & 36,4 & 8,90 & 9,19 & 11,40 & 9,04 & 6,34 & 6,06 & 4,23 & 3,35 & 2,77 & 2,53 & 2,65 & 7,59 & 74,05 \\
\hline 5 & 45,5 & 8,44 & 8,96 & 10,58 & 8,68 & 5,86 & 4,81 & 3,72 & 2,98 & 2,46 & 2,16 & 2,48 & 7,54 & 68,70 \\
\hline 6 & 54,5 & 7,49 & 8,05 & 8,52 & 8,47 & 5,72 & 4,79 & 3,67 & 2,93 & 2,43 & 1,91 & 2,47 & 5,21 & 61,66 \\
\hline 7 & 63,6 & 4,85 & 7,75 & 6,29 & 7,86 & 4,38 & 3,58 & 2,77 & 2,42 & 1,98 & 1,91 & 2,33 & 5,15 & 51,27 \\
\hline 8 & 72,7 & 4,24 & 7,37 & 5,09 & 6,09 & 4,33 & 3,39 & 2,64 & 2,09 & 1,73 & 1,51 & 2,20 & 4,13 & 44,82 \\
\hline 9 & 81,8 & 2,83 & 5,77 & 4,35 & 5,13 & 4,12 & 3,14 & 2,43 & 1,94 & 1,61 & 1,34 & 2,06 & 3,16 & 37,88 \\
\hline 10 & 90,9 & 1,02 & 2,99 & 1,97 & 2,17 & 1,30 & 1,19 & 0,90 & 0,71 & 0,62 & 1,26 & 1,64 & 2,56 & 18,32 \\
\hline Q80\% & 80 & 3,11 & 6,09 & 4,50 & 5,33 & 4,16 & 3,19 & 2,47 & 1,97 & 1,63 & 1,38 & 2,09 & 3,36 & 39,27 \\
\hline Q90\% & 90 & 1,20 & 3,27 & 2,21 & 2,47 & 1,58 & 1,38 & 1,05 & 0,83 & 0,72 & 1,27 & 1,68 & 2,62 & 20,28 \\
\hline Q95\% & 95 & 0,56 & 1,64 & 1,09 & 1,19 & 0,71 & 0,65 & 0,49 & 0,39 & 0,34 & 0,70 & 0,90 & 1,41 & 10,08 \\
\hline
\end{tabular}

\section{Kebutuhan Air RKI ( Rumah tangga, Perkotaan, Industri )}

Sesuai SNI 6728.1 Tahun 2015, Kebutuhan Air RKI dihitung dengan cara menjumlahkan kebutuhan air untuk rumah tangga, perkotaan, dan industri.

Contoh perhitungan kebutuhan RKI bulan Januari tahun 2017 sebagai berikut :

Kebutuhan air rumah tangga total bulan Januari $2017=386.959,145$

Kebutuhan air perkotaan total bulan Januari $2017 \quad=77.391 ., 829$

Kebutuhan air industri total bulan Januari $2017 \quad=167.400$

Kebutuhan air RKI bulan Januari $2017=386.959,145+77.391,829+167,400=464518,374$

\section{Kebutuhan Air Peternakan}

Perhitungan kebutuhan air rata-rata untuk peternakan tergantung pada populasi/jumlah ternak dan jenis ternak. Secara umum kebutuhan air untuk ternak dapat diestimasikan dengan cara mengalikan jumlah ternak dengan tingkat kebutuhan air berdasarakan persamaan berikut :

$\mathrm{Qe}=(\mathrm{q}(1) \times \mathrm{P}(1)+\mathrm{q}(2) \times \mathrm{P}(2) \mathrm{q}(3) \times \mathrm{P}(3)$

Contoh total Kebutuhan Air Peternakan Desa Sumberagung Kecamatan Pracimantoro pada bulan Januari 2017 adalah $871720+272955+0+0=\mathbf{1 1 7 3 1 9 5}$ liter/bulan.

Kebutuhan Air untuk Irigasi pada DAS Alang

Luas sawah untuk padi dan Palawija MT2

Total sawah $=5796 \mathrm{Ha}$ 
Sawah untuk Padi

Sawah untuk Palawija

Persentase Luas tanah untuk padi

Persentase Luas tanah untuk Palawija

$$
\begin{aligned}
& =3357 \mathrm{Ha} \\
& =648 \mathrm{Ha} \\
& =(3357 / 5796) \times 100=0,64 \% \\
& =(648 / 5796) \times 100=0,14 \%
\end{aligned}
$$

\section{Neraca Sumber Daya Air}

Setelah semua kebutuhan air dihitung ( Kebutuhan Air RKI, Kebutuhan Peternakan, Kebutuhan Irigasi, Kebutuhan Perikanan, Kebutuhan Air Pemeliharaan Sungai), maka selanjutnya menjumlahkan semuanya menjadi kebutuhan air total. Perbandingan antara ketersediaan air DAS Alang dengan kebutuhan air DAS Alang akan menjadi neraca Air Daerah Aliran Sungai (DAS) Alang. Metode yang digunakan dalam menghitung neraca air pada penelitian ini sesuai SNI 6728.1 Tahun 2015.

Berikut analisis data neraca air DAS Alang bulan Januari tahun 2017 dan prediksi tahun 2018 :

Kebutuhan Air RKI

Kebutuhan Air Peternakan

Kebutuhan Air Irigasi

Kebutuhan Air Perikanan

Kebutuhan Air Pemeliharaan Sungai

Kebutuhan Air Total

Ketersediaan Air

Saldo

Kebutuhan Air RKI

Kebutuhan Air Peternakan

Kebutuhan Air Irigasi

Kebutuhan Air Perikanan

Kebutuhan Air Pemeliharaan Sungai

Kebutuhan Air Total

Ketersediaan Air

Saldo

$$
\begin{aligned}
& =343107,960 \mathrm{~m}^{3} / \text { bulan } \\
& =70791,4388 \mathrm{~m}^{3} / \text { bulan } \\
& =5142343,773 \mathrm{~m}^{3} / \text { bulan } \\
& =0 \mathrm{~m}^{3} / \text { bulan }
\end{aligned}
$$

$\left(\mathrm{Q}_{95}\right)=1496475,352 \mathrm{~m}^{3} /$ bulan

$=343107,960+70791,438+5142343,773+0+1496475,352$

$=7052718,524 \mathrm{~m}^{3} /$ bulan

$=3,11 \mathrm{~m}^{3} /$ detik (debit andalan Q80\%)

$=3,11 \times 60^{2} \times 24 \times 31$

$=8329543,618 \mathrm{~m}^{3} /$ bulan

$=$ Ketersediaan Air - Kebutuhan Air

$=8329543,618-7052718,524$

$=1276825,094 \mathrm{~m}^{3} /$ bulan (bulan Januari tahun 2017)

$=464518,374 \mathrm{~m}^{3} /$ bulan

$=70791,4388 \mathrm{~m}^{3} /$ bulan

$=7345849,406 \mathrm{~m}^{3} /$ bulan

$=0 \mathrm{~m}^{3} /$ bulan

$\left(\mathrm{Q}_{95}\right)=4163275,59 \mathrm{~m}^{3} /$ bulan

$=464518,374+70791,4388+7345849,406+0+4163275,59$

$=12044434,808 \mathrm{~m}^{3} /$ bulan

$=4,366 \mathrm{~m}^{3} /$ detik

$=3,11 \times 60^{2} \times 24 \times 31$

$=116955229,2 \mathrm{~m}^{3} /$ bulan

$=$ Ketersediaan Air - Kebutuhan Air

$=116955229,2-12044434,808$

$=-349205,611 \mathrm{~m}^{3} /$ bulan (prediksi bulan Januari tahun 2018)

Berikut adalah hasil neraca air tahun 2017 dan 2018 (prediksi) dalam bentuk grafik.

Neraca Air Tahun 2017

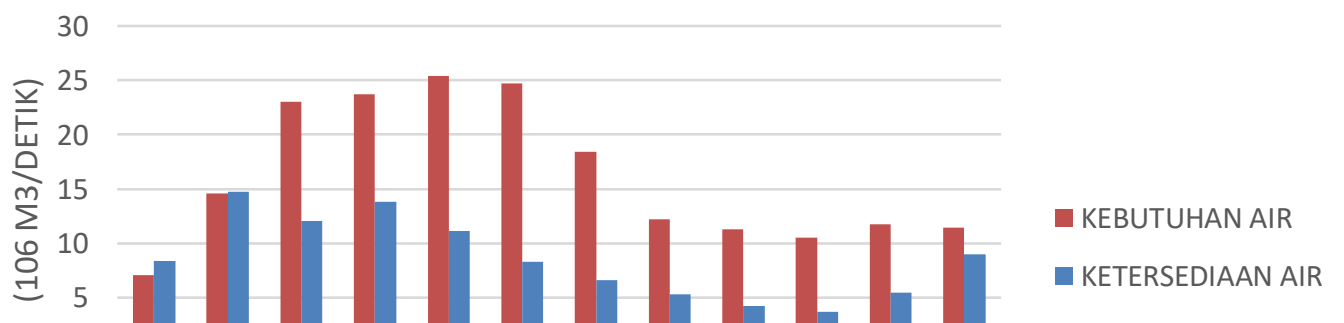


Gambar 3 Hasil neraca air tahun 2017 dalam bentuk grafik

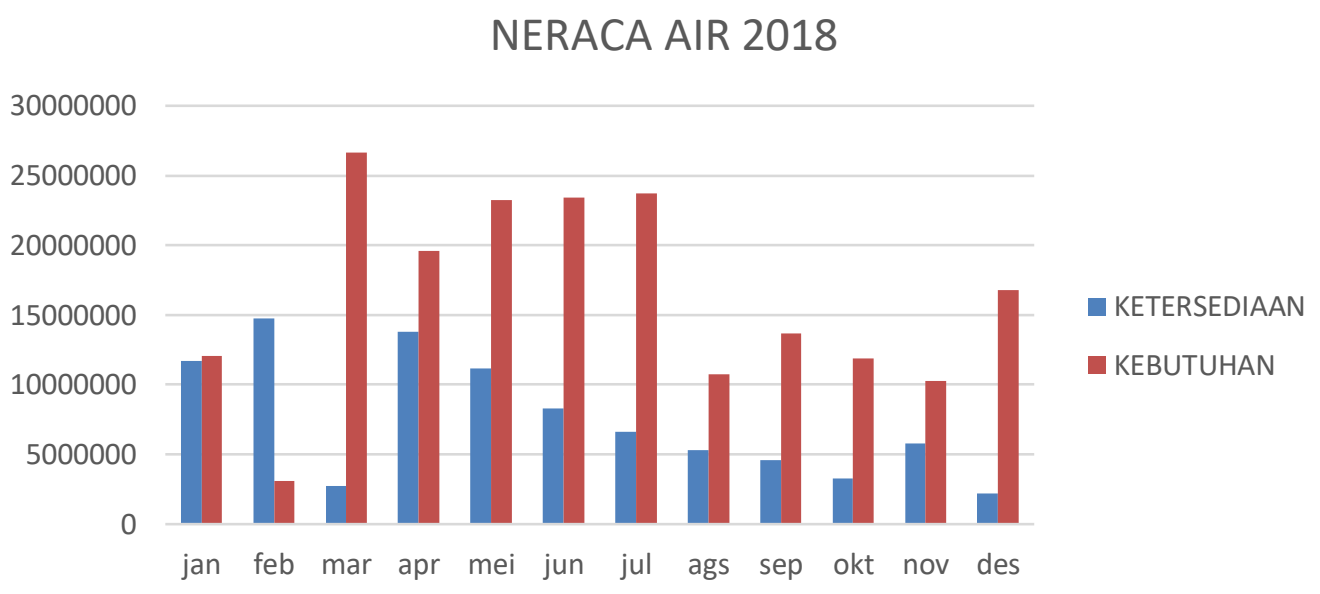

Gambar 4 Hasil neraca air tahun 2018 dalam bentuk grafik

\section{KESIMPULAN}

Berdasarkan penelitian yang sudah dilakukan, dapat ditarik kesimpulan, yang terdiri dari:

1. Neraca Air Tahun 2017

Pada DAS Alang terjadi saldo air hanya pada bulan Januari saja yaitu sebesar 1276825,094 $\mathrm{m}^{3}$ /bulan, sedangkan pada bulan Februari-Desember terjadi defisit air. Defisit terbesar terjadi pada bulan Juni dengan devisit sebesar 16460014,494 .

$\mathrm{m}^{3} /$ bulan.

2. Neraca Air Tahun 2018

Berdasarkan prediksi ketersedian air dan kebutuhan air yang sudah dilakukan. Pada DAS Alang terjadi saldo air pada bulan Februari saja yaitu sebesar 11655990,41 $\mathrm{m}^{3} /$ bulan, sedangkan pada bulan Januari, Maret-Desember terjadi defisit air. Defisit terbesar terjadi pada bulan Maret dengan devisit sebesar 23932009,41 m³/bulan.

3. Peta Neraca Air

Setelah mendapatkan neraca air maka dapat membuat peta neraca air yang berdasarkan hitungan peta saldo air sesuai standar SNI 6728.1 Tahun 2015. Berdasarakan perhitungan peta saldo air, peta neraca air tahun 2017 dan 2018 berwarna merah yaitu nilai saldo air kurang dari nol $(<0)$. 


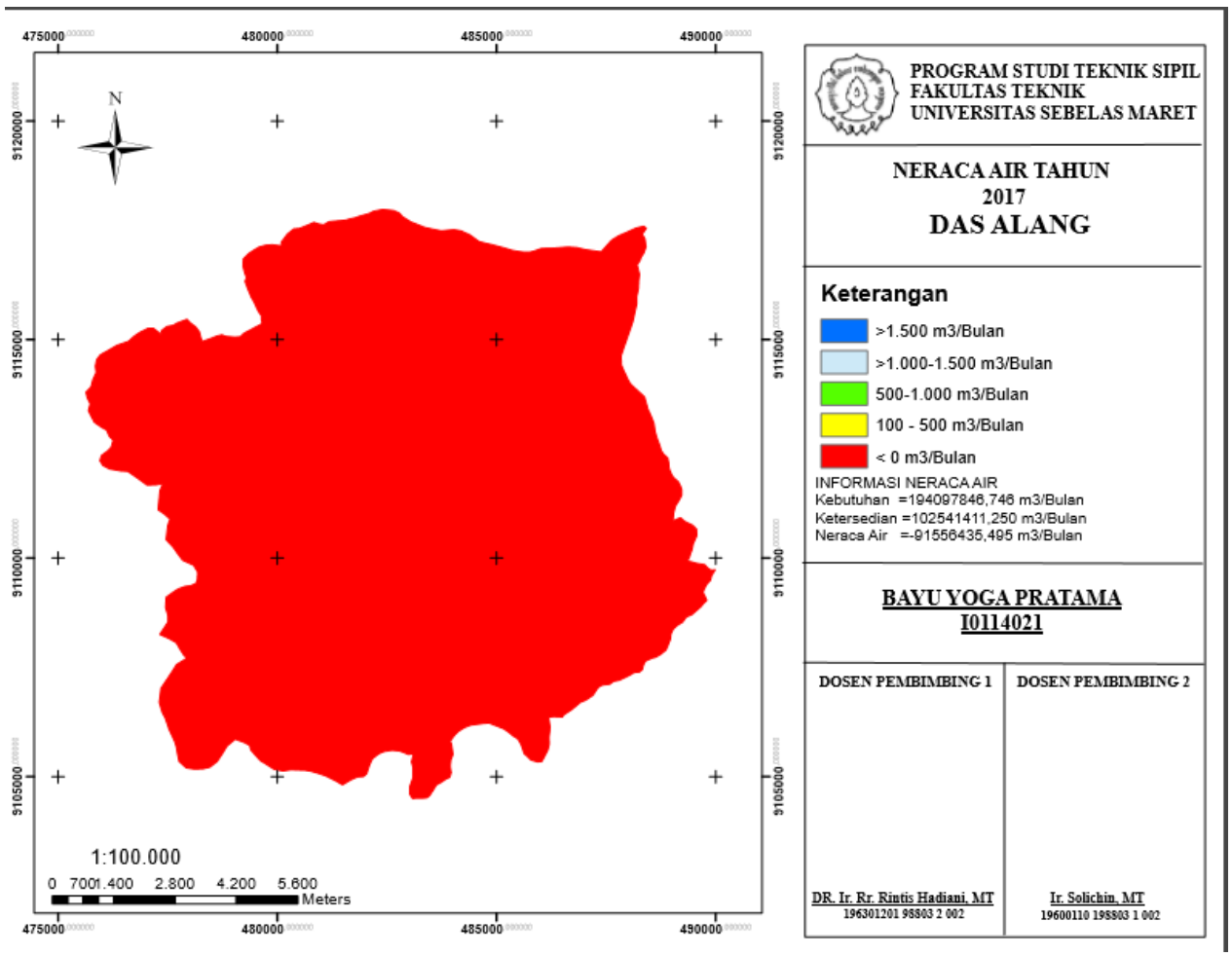

Gambar 5 Peta neraca air tahun 2017

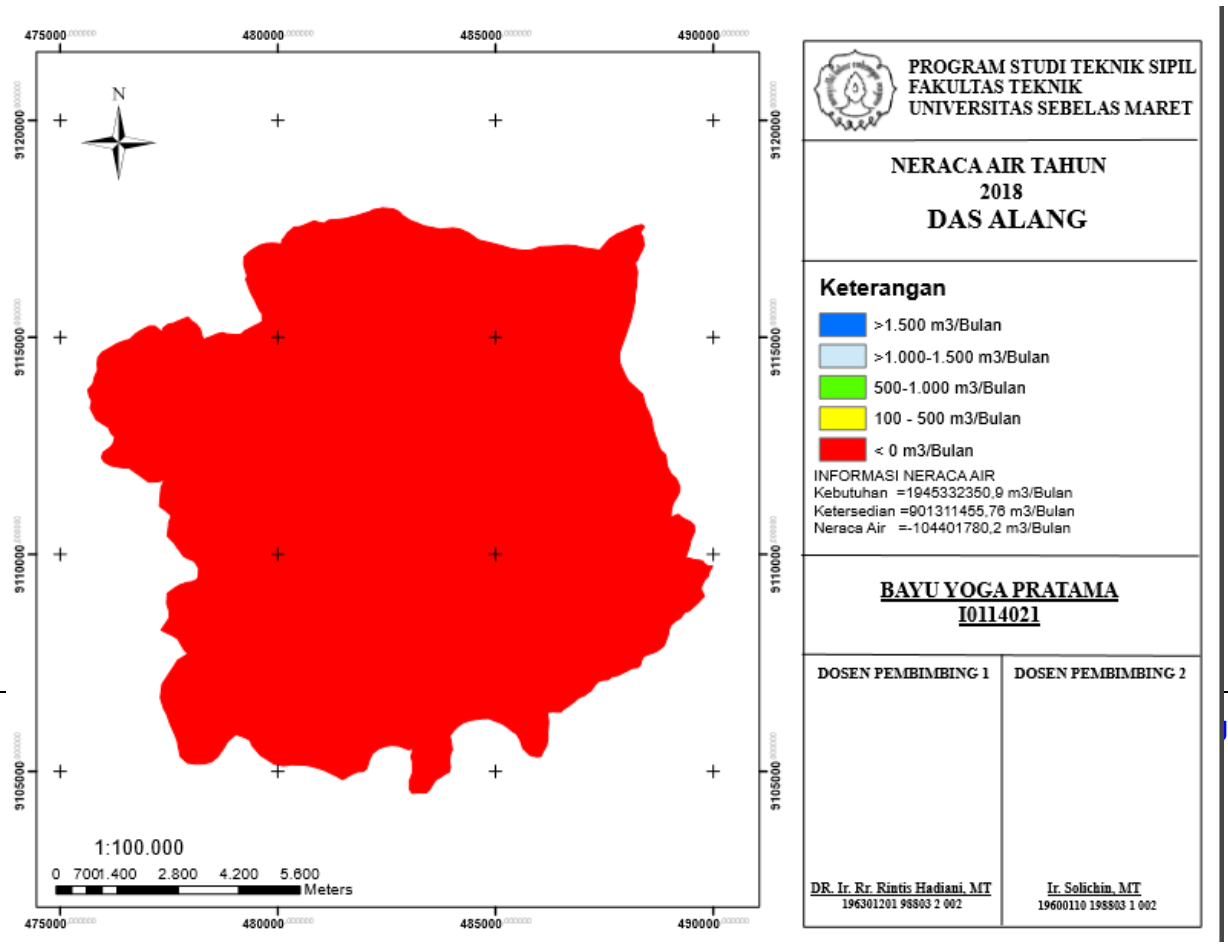


Gambar 6 Peta neraca air tahun 2018

\section{REKOMENDASI}

1.Perhitungan debit menggunakan metode NRECA, dalam perhitungan debit masih terdapat metode lain yang dapat dilakukan.

2. Data hujan yang dipkai adalah 10 tahun yaitu 2008-2017, dapat diubah rentangnya sesuai kebutuhan.

3. Penelitian ini hanya memperhatikan aliran permukaan ( run off), sehingga perlu adanya penelitian lebih lanjut mengenai sumber daya air tanah.

4. Prediksi data hujan tidak hanya menggunakan Minitab 18 tetapi bisa menggunakan software lainya seperti Neural Network, Matlab, dan sebagainya.

\section{REFERENSI}

Ferry. 2015. Simulasi Prediksi Pola Tata Tanam Di DAS Tirtomoyo Berdasarkan Neraca Air (Tugas Akhir). Surakarta : Universitas Sebelas Maret.

Zulkipli. 2012. Analisis Neraca Air Permukaan DAS Renggung untuk. Memenubi Kebutuban Air Irigasi dan Domestik Penduduk Kabupaten Lombok Tengah. Jurnal teknik Pengairan, vol 3, No 2. Malang : Universitas Brawijaya.

Anonim. 2015. SNI 6728.1:2015. Penyusunan Neraca Spasial Sumber Daya Alam-Bagian 1 : Sumber Daya Air, Jakarta : Badan Standarisasi Nasional (BSN). 